\title{
Da dança e do devir: o corpo no regime do sutil
}

\author{
Vilene Moehlecke \\ Tania Maria Galli Fonseca ${ }^{\star \star}$
}

RESUMO

Pretendemos discutir o "corpo que dança" e sua relação com o tempo em sua dimensão paradoxal. Trata-se, pois, de um tempo rizomático e complexo, tomado por virtualidades e desprendido do movimento e que se abre ao impessoal e às singularidades. Então, para temporalizar o corpo que dança, é preciso relançá-lo ao acontecimento, ao devir imperceptível e às pequenas percepções. Entendemos que a dança pode ser um modo de subjetivação em constante movimento. Por fim, esperamos romper com a postura neutra na produção de conhecimento, apostando na própria implicação como elemento fundamental para a construção do problema a ser pensado e discutido.

Palavras-chave: Corpo que dança. Tempo. Acontecimento. Pequenas percepções. Psicologia.

\section{On dance and becoming: the body on the dimension of the subtle}

\begin{abstract}
We intend to discuss the "dancing body" and its relation to time in its paradoxical dimension. It is therefore about a rhizomic and complex time, overtaken by virtualities and loosened from movement, and which may open itself to the Impersonal and singularities. Then, in order to temporalize the dancing body, we have to relaunch it to the Event, to the imperceptible becoming and the small perceptions. We understand that the dance can be a mode of subjectivation in constant process. Thus, we hope to break with the neutral position in the knowledge production, regarding one's own implication as a basic element for the construction of the problem to be thought and discussed.

Keywords: Dancing body. Time. Event. Small perception. Psychology.

^ Psicóloga, bailarina e mestranda do Programa de Pós-Graduação em Psicologia Social e Institucional/ UFRGS. Graduação em Psicologia Social e Institucional/UFRGS. Endereço: Rua Osvaldo Aranha, 110 B. São Leopoldo/RS. Bairro Centro. Cep: 93010-040. E-mail: pirueta7@ pop.com.br

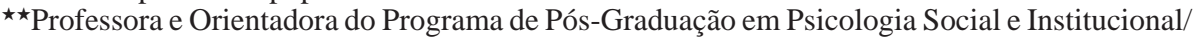
UFRGS.E-mail: tfonseca@ via-rs.net
\end{abstract}




\section{ENSAIANDO ENTRADAS}

Essa escrita é tomada por diversos atravessamentos. A Psicologia perpassa nossas trajetórias e estudos, uma vez que dela advém nossa formação acadêmica e nossas práticas enquanto pesquisadoras e profissionais da área. Além disso, não podemos deixar de lado as influências da Filosofia da diferença, que nos fazem aventurar em leituras de Nietzsche e Gilles Deleuze, dentre outros, com o intuito de buscarmos um entendimento singular do que nos propomos a problematizar. Por fim, a dança contemporânea é outra grande influência nesse trabalho, visto que o ato de dançar é aqui transmutado em objeto de estudo de minha dissertação de mestrado junto ao Programa de Pós-Graduação em Psicologia Social e Institucional da UFRGS.

É assim, na confluência de tais encontros, que se põe em processo um devir psicólogo que dança e se põe a inventar novos movimentos e passos, rompendo com a idéia de uma postura imóvel e identitária em relação a conceitos e práticas; um devir pesquisador que rompe com a noção de neutralidade, apostando na própria implicação como elemento fundamental para a criação dos problemas discutidos e investindo no intempestivo como constitutivo de sua pesquisa; um devir bailarino que nos movimenta e convida a produzir novos conhecimentos que entrelaçam a dança a outros saberes. Falamos, pois, de corpos que se aventuram nas intensidades do pensamento e, sendo assim, propõem-se a pensar o corpo que dança e as complexidades desse tempo dançante, o que enseja, ainda, por fim, um devir escritor, que se deixa atravessar por estranhos devires para compor uma escrita inventiva, um "escritor feiticeiro", como diria Deleuze e Guattari (1997). Desse modo, o corpo dança e convida o seu pensamento a dançar.

O presente texto constitui-se, portanto, como o reflexo de nossa pesquisa, que problematiza a potência do corpo que dança e sua relação com o tempo, isto é, propõe-se a discutir o que significa temporalizar o corpo que dança, quais seriam seus paradoxos, suas linhas de fuga e de errância, suas segmentaridades e dificuldades, seus rigores, suas aventuras, seus embates, suas transformações. Concebemos, para tanto, a dança como modo de subjetivação orientado para um permanente movimento, já que nos aponta uma possível forma micropolítica de existir de múltiplas maneiras.

Quando pensamos o "corpo que dança", constatamos o inevitável: esse corpo percorre "outro tempo". Não se situa apenas no escoamento linear das horas, dos minutos e tampouco se deixa capturar pela lógica da aceleração e do imediatismo. Em que consiste, pois, essa dimensão diferenciada do tempo? Como conectá-la ao corpo sob um regime sutil? De que nos fala esse tempo em seu caráter paradoxal, que rompe com a sucessão e com a cronologia linear de fatos e gestos? São essas, portanto, as questões iniciais que nos incitam a levar adiante nosso estudo.

\section{A abertura ao impessoal - Movimentos de mundo}

Para entendermos um tempo que se desprende da noção de linearidade, buscamos Deleuze (2002), tomando mais precisamente seu trabalho sobre as ima- 
gens do tempo e sua relação com o que denomina Impessoal. Para esse autor, a imanência, o campo transcendental, isto é, o Impessoal, opõe-se a tudo o que compõe o mundo do sujeito e do objeto, desprendendo-se da idéia de identidade ou individualidade e retratando uma duração qualitativa da consciência sem um "eu". O campo transcendental se caracteriza pela multiplicidade, num movimento em que não há começo nem fim. Nesse sentido, o Uno é sempre um acontecimento, uma singularidade, uma vida, isto é, o índice de uma multiplicidade. O Impessoal, portanto, se refere ao Fora, sendo pura corrente de consciência a-subjetiva, pré-reflexiva impessoal, um plano de imanência, o plano de "uma vida", neutra, para além do bem e do mal, singular, puro acontecimento não-submetido às regras de organização do cosmos, do mundo e do eu. Para Deleuze (2002, p. 11), "Há qualquer coisa de selvagem e de potente num tal empirismo transcendental". Trata-se da própria vida imersa no caos, extra-ser aberto a todos os devires. Entre vida e morte de um homem, há um momento que não é nada mais do que uma vida, impessoal e singular, que se desprende da identidade individual, uma vida de pura imanência.

René Schérer (2000), ao analisar o conceito de Impessoal de Deleuze, nos remete à noção de acósmico, significando um Extra-Ser, aberto a forças; um índice da mais alta potência de vida. Fala-se, aqui, de um "empirismo transcendental", que dispensa o "Eu penso" da tradição cartesiana e também da consciência. Falase do Ser enquanto acontecimento, enquanto modo ou singularidade. O lugar do Impessoal é uma espécie de camada que se coloca entre as palavras e as coisas. Algo que se coloca em meio de um "neutro", o lugar do Impessoal ou o Plano que o Impessoal desdobra. Para Peter Pál Pelbart (1989), esse Fora se compõe por tensões entre-forças, que dizem das diferenças qualitativas, das diferenças de intensidades das forças e de sua ação umas sobre as outras. Desse modo, o 'neutro' do Impessoal não se caracteriza por um puro vazio, por ausências de sentidos, ou por uma entidade-vácuo; não se refere a um espaço homogêneo, absoluto e originário, sendo caracterizado exatamente por um estado intenso ou intensivo, em que o que há são relações de forças. É preciso salientar que "na relação neutra estamos expostos ao Fora e, por conseguinte invadidos pelas entre-forças, isto é, pelas intensidades" (PELBART, 1989, p. 123). Portanto, o Impessoal se faz através de um plano intensivo, de um jogo de forças e de um jogo do acaso, uma vez que, se o Fora se refere ao domínio das forças, ele também se refere ao domínio do acaso, do Intempestivo. É nesse sentido que as Forças, o Fora e a Diferença formam uma tríade indissolúvel e não podem ser pensadas isoladamente.

O Impessoal é atravessado por um outro tempo. Este não é mais visto como ser, como "é", mas como "entre", como conjunção "e". Conforme Deleuze e Parnet (1998), alguma coisa ocorre entre os elementos ou entre os conjuntos: o "e, e, e" é a própria gagueira, a possibilidade de percorrer o "entre". Mesmo quando houver apenas dois termos, há um 'e' entre ambos, que não é mais nem um, nem outro, nem um que se torna o outro, mas que constitui, precisamente, o Impessoal, a multiplicidade.

Essa vida indefinida não tem, ela própria, momentos, por mais próximos que estejam uns dos outros, mas apenas entre- 
tempos, entre-momentos. Ela não sobrevém nem sucede, mas apresenta a imensidão do tempo vazio no qual vemos o acontecimento ainda por vir e já ocorrido, no absoluto de uma consciência imediata (DELEUZE, 2002, p. 14).

Assim, o impessoal refere-se ao acontecimento puro, a uma vida, em sua plena potência e multiplicidade, constituindo-se, dessa forma, o paradoxo de que se trata, simultaneamente, de uma vida impessoal e, também, singular, já que o Acontecimento agencia a criação, a individuação, apagando a vida de uma individualidade, de um "eu”, em proveito da vida singular imanente a um homem. Os acontecimentos e as singularidades não fazem nada mais do que se atualizar nos sujeitos e nos objetos uma junção do mais impessoal e do mais singular. Evocando passagens e movimentos do eu individual que, muitas vezes, pode encontrar-se imobilizado, o Impessoal pode produzir o salto do corpo para o acontecimento puro, buscando uma vida em sua potência de forças. Para tanto, um corpo precisa se abrir e se conectar com a potência das forças do Impessoal, desprendendo-se do antigo eu 'imobilizado' e lançando-se no plano das multiplicidades do Fora.

Na dança, muitas vezes, o bailarino também precisará realizar "saltos" para se conectar com as potências do Impessoal. O corpo que dança "salta" para desbravar novos gestos e compor novas imagens, e, para tanto, é preciso que se desprenda do antigo "eu" que dançava, do antigo corpo. Referimo-nos, pois, a um corpo que procura ultrapassar-se, buscando sua potência e sua multiplicidade nas forças de um novo tempo, o tempo que rege as intensidades do Impessoal. Resta saber, como nos diz Deleuze (1990), de que forma o bailarino passa de uma motricidade pessoal a um elemento supra-pessoal, a um movimento de mundo que a dança vai traçar. Há, pois, um "grau zero", como que uma hesitação, um atraso, um "neutro", algumas falhas preparatórias ou, ao contrário, um nascimento brusco, entre o passo motor e o passo da dança. Ao dançar, o bailarino irá transformar seus gestos pessoais em movimentos de mundo, que ultrapassam a situação motora, podendo voltar a esta. É dessa forma que o corpo que dança pode conectar-se com o Impessoal, o plano de imanência, através da criação de movimentos aberrantes, movimentos de mundo, criados nas passagens "entre-forças" e regidos pela lógica rizomática do “e, e, e,”. O corpo que dança procura, por meio de sua gagueira hesitante, saltar para a produção de sua própria língua. A dança se torna, então, um meio de entrar em outro mundo, no mundo do outro. Torna-se outramento, diferenciação. Ao se conectar com as forças do Impessoal, o corpo que dança se desprende de sua identidade e se abre para a criação de novos contornos, experimentando, assim, gestos de mundo e novos modos de existir.

\section{O TEMPO PARADOXAL - RUPTURAS COM UMA LINEARIDADE}

Para entrarmos na discussão do que implica temporalizar o corpo que dança, precisamos, junto com isso, problematizar a questão do tempo, na tentativa de romper com a idéia de um tempo enquanto modelo linear e cronológico.

A partir das discussões feitas sobre o Impessoal, entendemos que o bailarino precisa abrir-se às forças de uma vida, compondo um outro tempo ao seu cor- 
po, um tempo paradoxal que o transforma ao conectá-lo à sua dimensão virtual. Conforme Deleuze (2002), uma vida contém virtualidades, acontecimentos, singularidades. $\mathrm{O}$ virtual não é algo a que falte realidade; trata-se de algo que produz realidades, atualiza potências, que é sem ser dado, como um contorno que existe sem ser fixo, algo indeterminado que faz o corpo mudar, transportando-o a novos movimentos e passagens. "O plano de imanência é, também ele, virtual, na medida em que os acontecimentos que o povoam são virtualidades" (DELEUZE, 2002, p.16). O virtual não está, portanto, inserido num domínio de perda da realidade, mas ele se faz a partir da multiplicidade, das forças que produzem a diversidade do corpo. Deleuze (1990, p. 90) salienta que o virtual opera juntamente com o atual: "distintos, mas indiscerníveis, assim são o atual e o virtual, que não param de se trocar". Éric Alliez (1996), ao discorrer sobre a filosofia do virtual de Deleuze, salienta que o plano de imanência compreende um tempo de coexistência entre virtual e atual, de criação e complexidade.

Dessa maneira, qualquer elemento atual é povoado por uma névoa de imagens virtuais, operando o virtual sob um princípio de incerteza e de indeterminação, seguido de um movimento de criação. "A atualização do virtual é a singularidade" (ALLIEZ, 1996, p. 51). No plano de imanência, pode ocorrer uma dissolução do atual, fazendo com que a potência das virtualidades ganhem mais consistência. É assim que o virtual cria quando se atualiza, mas ele é, também, aquilo que se modifica e se transforma: um tempo de plasticidade e de invenção. Desse modo, virtual e atual compõem um tempo coextensivo e inventivo, em que o tempo não é somente o que cria, mas, sobretudo, o que se cria e se ultrapassa.

Temporalizar consiste, pois, em passar do virtual ao atual e do atual ao virtual. A fim de temporalizar o corpo, precisamos virtualizá-lo, abrindo-o ao plano de multiplicidades, a um tempo de coexistência entre atual e virtual. Ao virtualizarmos o corpo, estamos provocando o desmanche do corpo atual e a possibilidade da atualização de outros corpos virtuais, que se encontravam num campo de indeterminação e de virtualidade. Nesse sentido, o corpo que dança é composto de um corpo atual, porém, ele é, simultaneamente, povoado por uma névoa de outros corpos virtuais - um tempo virtual. Dançando, os corpos virtuais podem-se atualizar, ganhando espaço e força na coreografia.

Para Deleuze (1990), além de problematizar a coexistência entre atual e virtual, podemos pensar o tempo a partir de imagens: imagem-movimento e imagem-tempo. Na lógica da primeira, o tempo é concebido como unicamente atual, sucessivo, obedecendo a uma certa organicidade e previsibilidade. Nesse sentido, está subordinado ao movimento, uma vez que aquele é a própria medida deste. Na imagem-movimento, há um espaço bem qualificado que supõe uma ação que o desvele, ou suscite uma reação que se adapte a ela ou a modifique - situações sensório-motoras. Isso significa dizer que se trata de um tempo com um espaço bem delimitado, composto por ações e reações que seguem uma lógica linear: primeiramente, ocorre uma ação e, posteriormente, uma reação, que pode ser de adaptação à ação primeira ou de contestação àquela. Por isso, o tempo na imagemmovimento está subordinado às ações, ao movimento, respeitando um certo ordenamento. Aqui, o corpo está engajado nesse movimento, sendo este composto 
por uma temporalidade sucessiva. Além disso, nessa forma de tempo, produzemse imagens-clichês, uma vez que, normalmente, percebemos parte da coisa, conforme nossos interesses, e a transformamos em clichês. Estes se referem a modelos de imagens a serem seguidos, visto que há uma lógica das ações a ser respeitada, que produz imagens-clichês, isto é, uma imagem sensório-motora da coisa. Por todos esses motivos, entendemos que o corpo, na imagem-movimento, se faz a partir de um tempo linear e atual e, sendo assim, busca o seu mantenimento; não há, aqui, uma transformação do corpo, ou uma atualização de outros corpos virtuais.

Entretanto, segundo Deleuze (1990), algo se dá para além da imagem-movimento. Por mais que haja uma ação, por mais que o personagem se mova, a situação extravasa por todos os lados suas capacidades motoras, e lhe possibilita ver e ouvir o que não é mais passível de ação. Trata-se da imagem-tempo, na qual o tempo já não mais se subordina ao movimento, mas este se transforma na perspectiva do tempo. A imagem-tempo se faz a partir de encontros que provocam uma transformação de ambas as partes, visto que os próprios objetos conquistam uma realidade material autônoma que os faz valerem por si mesmos. Isso significa dizer que, na imagem-tempo, qualquer coisa é passível de transformação, de passagem, independentemente de haver uma ação ou não; mais do que uma ação, é fundamental que haja o encontro.

Além disso, na imagem-tempo, o personagem está entregue a uma visão, mais do que engajado numa ação, já que a imagem não é mais somente sensóriomotora, mas ótica e sonora, investida pelos sentidos. Numa situação ótica e sonora, algo poderoso demais, ou injusto demais, ou belo demais excede nossas capacidades sensório-motoras. Dessa forma, é preciso romper com as imagens-clichês da imagem-movimento, produzindo novas formas de imagem, com seus excessos e com seus transbordamentos. E, paradoxalmente, isso pode ocorrer através de uma situação-limite ou algo bem banal, havendo, pois, uma aposta maior do cotidiano como incentivador da invenção. Então, há um investimento de todo o corpo para que a imagem-movimento se quebre, deixando emergir situações ótico e sonoras, isto é, um corpo investido pelos sentidos, a imagem-tempo.

Em relação à sua ocupação do espaço, a imagem-tempo se estabelece no "espaço qualquer", esvaziado, desconectado, diferentemente da imagem-movimento, que se estabelece num espaço bem definido. $\mathrm{O}$ espaço vazio revela devir, mudança, passagem. Há um "ponto de indiscernibilidade" na imagem-tempo entre objetivo e subjetivo, real e imaginário. Isso quer dizer que se trata de um tempo enquanto virtualidade, em que passado e futuro podem coexistir com a imagem presente, um tempo paradoxal.

Deleuze (1990) discorre sobre a questão do movimento nas duas imagens do tempo. Assim, os movimentos normais subordinam o tempo, atestando a presença da imagem-movimento. Já os movimentos aberrantes atestam uma anterioridade do tempo, o que não o denota como pré-estabelecido e fechado em a prioris. Revela-o como abertura infinita, anterioridade a qualquer movimento normal definido pela motricidade, anterior ao desenrolar regrado de qualquer ação, isto é, 
como tempo intensivo e não linear. Ora, se assim ocorre, não consiste a dança numa eterna busca por movimentos aberrantes e descentrados, que contenham em si um caráter de insubordinação ao tempo linear?

Cabe lembrar, ainda, que as duas imagens do tempo coexistem, a imagemmovimento não desaparece, mas passa a existir como a primeira dimensão de uma imagem que não pára de crescer em dimensões múltiplas. Portanto, a imagemmovimento precisa se quebrar para deixar surgir outro tipo de imagem, uma imagem ótico-sonora, que faz surgir "a coisa", em seu excesso de horror ou de beleza, nem boa, nem má - a imagem-tempo - que produz uma quebra da imagem-clichê. Assim, a imagem não é mais somente sensório-motora, mas também ótica e sonora, investida pelos sentidos.

Ao dançar, falamos em imagem-movimento, mas também em imagem-tempo. Sabemos que, no caso da dança, o bailarino precisa, simultaneamente, conservar os seus centros, à procura de um eixo em seu corpo - imagem-movimento mas também ele precisa descentrá-los - imagem-tempo. Através da imagem-tempo, o bailarino não subordinará o seu corpo ao movimento, e poderá atualizar outros corpos virtuais, desprendendo-se dos antigos. Esse tempo de coexistência e multiplicidade pode ser visualizado na dança contemporânea. Passos do balé clássico que nos revelam uma leveza e uma técnica apurada em que as sucessões dos movimentos devem ser respeitadas estão presentes nesse estilo de dança. Por outro lado, também nos deparamos com movimentos de expressão e agilidade corporal criados mais recentemente, que demonstram a quebra das certezas, a saída do eixo e os movimentos descentrados. Portanto, o corpo requer um tempo enquanto linearidade, em alguns momentos, quando é preciso dispor da imagemmovimento, de uma seqüência dos passos a serem seguidos na coreografia. Entretanto, tal seqüência é, simultaneamente, quebrada, compondo-se uma imagemtempo, que se desprende das seqüências e linearidades e se joga num tempo enquanto devir, produzindo um corpo enquanto massa, que se revolve e se desdobra em novas configurações. Por isso, na dança percebemos a coexistência das imagens do tempo. Um tempo sucessivo e subordinado ao movimento coexiste à imagem-tempo, tornando-o paradoxal e desprendendo-o do movimento. É preciso respeitar a sucessão dos passos, a seqüência correta da coreografia. Entretanto, o corpo que dança se joga na complexidade dos gestos, tentando incansavelmente ultrapassá-los, recriá-los em novos agenciamentos do corpo.

Esse tempo de coexistência pode ser visto na imagem-cristal (DELEUZE, 1990). Um tempo de simultaneidade entre presente e passado, tempo em que o passado não sucede ao presente que ele não é mais, mas coexiste com o presente que foi. $\mathrm{O}$ presente é a imagem atual e seu passado contemporâneo, a imagem virtual, imagem especular. E, uma vez que passado e presente coexistem, é preciso que o tempo se desdobre a cada instante em presente e passado, é necessário que o tempo se cinda ao mesmo tempo em que se afirma ou desenrola, fazendo passar todo o presente e conservando todo o passado. Ele consiste nessa cisão, nesse desdobramento, e isso é o que se vê na imagem-cristal: a perpétua fundação do tempo, o tempo não cronológico dentro do cristal, Cronos e Aïon. 
O movimento do bailarino se forma a partir de unidades espaço-tempo. Trata-se, pois, do tempo do "Acontecimento": a passagem do Cronos ao Aïon, isto é, do tempo cronológico ao tempo intensivo, das afecções. Cronos é o tempo da representação, da profundidade, já Aïon é o tempo da superfície, da "duração", do "Acontecimento". Aïon é a "pura forma vazia do tempo, que se liberou de seu conteúdo corporal presente" (PELBART, 1998, p. 72). Passar de Cronos a Aïon significa, pois, devolver as coisas à sua própria imanência e não somente à representação que se tem delas. Entretanto, há que se voltar à representação, quando for necessário. A dança, como outras formas de Arte, pode promover essa passagem: ir além do plano da representação. Trata-se de um tempo de criação, de agenciamento, de composição de novas formas e de contato com a dimensão sutil do Impessoal. Temporalizar o corpo pode se referir, também, a passar de Cronos a Aïon, isto é, ir além da representação das coisas, abrindo-se ao plano de imanência.

O tempo de Aïon é o tempo do Acontecimento (DELEUZE, 1990), ou seja, o tempo coextensivo aos devires, ao meio, ao intempestivo, à cesura, ao Impessoal. Segundo Pelbart (1998), querer o acontecimento não significa querer o que acontece, mas algo "no que acontece", sendo este algo não da ordem de um presente ou de uma eternidade, mas no sentido de um Impessoal. São todas as possibilidades passadas, futuras, ali concentradas. Assim, o bailarino sabe quando sua dança se fez num tempo do acontecimento, ou em que momento foi preciso "se proteger" e buscar a sua conservação. O corpo que dança aprende a se "entregar", mas de uma forma sutil.

José Gil (2001) nos diz que o "Acontecimento" é real, corporal, modificando a "duração" dos gestos do bailarino. Isso vai depender do regime de energia utilizado em cada movimento. O espaço-tempo do corpo nasce a partir da energia que lhe é imanente e não é fixo, mas varia conforme as velocidades utilizadas, os desdobramentos. Assim, se um movimento mantiver o regime de energia anterior, não se produz, ali, um acontecimento. Em contrapartida, um pequeno gesto, por mais simples que seja, pode produzir acontecimento se garantir uma certa mudança ou irrupção de sentidos na coreografia. Então, eis mais um paradoxo do tempo no corpo que dança: ele necessita da sucessão e, simultaneamente, do "Acontecimento". "A dança compõe-se de sucessões de micro-acontecimentos que transformam sem cessar o sentido do movimento" (GIL, 2001, p.66). Uma coreografia pode ser simples, sutil, inocente, mas ela terá brilho e força se o bailarino for capaz de produzir acontecimentos em seu corpo ao longo de seus gestos dançados. Ele não precisa mudar radicalmente de movimento, ou realizar um salto difícil para que o "Acontecimento" se faça, é preciso que o corpo se transforme, buscando a energia em cada instante, em cada olhar, em cada forma, em cada parte do seu corpo. Então, um simples gesto, uma leve mudança na direção do olhar, um sorriso que se abre, um deslizar do corpo, uma pequena alteração já pode ser dispositivo para o "Acontecimento".

Desse modo, para propor a ruptura com um tempo linear e subordinado ao movimento, é preciso pensar em outras formas do tempo: um tempo de coexistência entre atual e virtual, um tempo conectado às forças do Impessoal, um tempo que se desprende do movimento, um tempo do "Acontecimento". Isso nos faz 
pensar o tempo em seu caráter paradoxal, para além de uma linearidade ou de uma unidade. Deleuze e Guattari (1995) deslocam um termo da botânica, o rizoma, para pensar esse tempo complexo e contrapô-lo ao tempo da arborescência.

A imagem da árvore serve para pensar a sucessão, a hierarquia, os sistemas organizados com centro definido: tempo da representação e da unidade. O tempo como rizoma, entretanto, não se remete ao Uno, nem dele deriva, uma vez que retrata um tempo em sua multiplicidade; não há um início nem um fim, mas um "entre", configurando-se numa rede complexa e sem centro. Pode-se "saltar" de um ponto a outro muito distante, sem mediações, intempestivamente; por isso, já não se pensa o tempo enquanto um fluxo, mas como uma massa que se dobra e que cria novas configurações. Em vez de um rio correndo, o tempo rizomático assemelha-se a uma terra com seus estratos em constante movimento, significando um tempo complexo, que se torce, se movimenta, se dobra, passa e não passa, potencializa sua multiplicidade, o devir. O tempo enquanto rizoma é composto por sistemas a-centrados, não-hierárquicos e a-significantes, feito de direções movediças. Diferentemente da imagem da árvore, que articula e hierarquiza os decalques, o rizoma vai além do plano da representação: desterritorializa, reterritorializa, constitui um inconsciente enquanto usina de criação. Compõe-se de um "meio" pelo qual cresce e transborda, sendo que, nessa acepção,

o meio não é uma média; ao contrário, é o lugar onde as coisas adquirem velocidade. Entre as coisas não designa uma correlação localizável que vai de uma para outra e reciprocamente; mas uma direção perpendicular, um movimento transversal que as carrega uma $e$ outra, riacho sem início nem fim, que rói suas duas margens e adquire velocidade no meio (DELEUZE; GUATTARI, 1995, p. 37).

Apesar de haver essa oposição entre arborescência e rizoma, na prática os dois tempos ocorrem simultaneamente. Um rizoma é feito de linhas de segmentaridade e estratificação, mas também de linhas de fuga e de desterritorialização. Ou seja, "existem nós de arborescência nos rizomas, empuxos rizomáticos nas raízes" (DELEUZE; GUATTARI, 1995, p.31). Portanto, deparase com um tempo paradoxal, no qual rizoma e árvore, variados tempos, se misturam.

Isso pode ser sentido na dança. A sensação da passagem do tempo, ao dançar, denota sua complexidade. Há tempos em que o corpo atende à linearidade, respeitando a ordem dos movimentos e sua harmonia com a música; é um tempo enquanto arborescência, mantenimento e conservação de sentidos. Contudo, se a dança pode supor um tempo como rizoma, então, o bailarino, ao dançar, sente os devires tomarem e transportarem seu corpo para novos corpos; ele sente o tempo rachando, cindindo-se, descentrando-se e crescendo pelos meios. Às vezes é como se o tempo escoasse por entre os gestos do bailarino, num único instante. Em outros momentos, o corpo que dança se entrega de tal forma ao movimento, que, após um espetáculo de uma hora, por exemplo, o bailarino tem a sensação de ter dançado por uma vida inteira. Os elementos do tempo também se tornam múlti- 
plos, portanto, os minutos podem transformar-se em horas, assim como as horas, em segundos.

Um movimento dançado pode conter esse caráter temporal do corpo, sua possibilidade de "durar" e de transformar-se em outro gesto, em outro material expressivo. Deleuze (1999), discorrendo sobre o tempo enquanto "duração", um conceito de Bergson, discute um ritmo de duração, um processo de dissolução, uma maneira de ser no tempo - algo difere por natureza não só das outras coisas, mas de si mesmo. Além disso, a "duração" não se limita a uma experiência psicológica, pois se torna a essência variável das coisas - o tempo: um finito ilimitado, sendo o cerne da duração a multiplicidade. Um "corpo que dura" é diferente do "corpo duro" de certos modos de ser na contemporaneidade. O primeiro requer uma "duração", formas e forças como possibilidades de se transmutar, de envolver dentro e fora, profundidade e superfície, simultaneamente, abrindo possibilidades para que novos corpos se façam. Trata-se de uma passagem, de uma mudança, de um devir, mas de um devir que dura, de uma mudança que é a própria substância. Já o “corpo” duro’ não pretende essa transmutação, pelo contrário, ele preza por seu "mantenimento", por sua "identidade" e organização. Um corpo preso em sua "identidade" fecha-se num passado inquestionável, numa retenção da sucessão. Trata-se de um corpo que dá as costas para o tempo, fechando-se para o devir.

André do Eirado Silva (1997) fala-nos de uma determinada temporalidade que afasta os efeitos da "duração", impedindo o acesso ao virtual. Tal subjetividade volta as costas ao "se fazendo do tempo", só olhando para o que está totalmente feito; orienta-se para um tempo desdobrado na mais pura atualidade. Segundo o autor, o acesso ao virtual está implicado no conceito de "duração", uma vez que aquele requer uma forma de tempo que está em vias de se fazer, que está se fabricando, não sendo da ordem de algo já feito, já dado, dizendo respeito, portanto, à própria potência que algo tem para se transformar, produzindo novos sentidos. $\mathrm{O}$ virtual é o que se transforma e se ultrapassa, constituindo-se, pois, como a própria "duração". Dessa forma, pensamos o "corpo que dura" como aquele que se transforma e se ultrapassa.

Do mesmo modo, o bailarino precisa se perguntar, não raras vezes, em que pode se transformar o seu corpo. Se, por um lado, ele precisa dar as costas ao tempo e manter um certo conhecimento de sua técnica, por outro, ele deve esquecer o que sabe, para ultrapassar-se. Não se pode ficar sempre na ordem de um corpo já estabelecido e definido, que dá as costas ao tempo, mas é preciso que o corpo se virtualize, que se temporalize, que se abra à multiplicidade e à sua própria potência de transformação e de fabricação de outros corpos. Isso irá propiciar um outro tempo ao corpo que dança.

\section{Temporalizando o CORPo QUE DANÇA: A EMERGÊnCIA DO SUTIL}

Podemos, a partir daqui, colocar a nossa pergunta sobre o que significa temporalizar o corpo que dança. O que seria colocar tempo nas coisas ou no corpo? Como entendemos, a dança também contém essa simultaneidade do tempo. 
Nesse caso, podemos pensá-la como um modo de vida, um modo de subjetivação em processo. O corpo que dança se compõe a cada coreografia, estando ele subordinado ao tempo que se desdobra a todo instante. $\mathrm{O}$ bailarino, por sua vez, vive a atualidade do seu presente e, concomitantemente, conecta-se às forças de um corpo virtual, que o extravasa e o relança para o devir. Portanto, pensamos que o bailarino precisa criar um "outro tempo ao seu corpo", um tempo para além da sucessão e do movimento.

Para se desprender do movimento e da sucessão, o corpo que dança precisará se lançar aos devires, uma vez que, se ele se grudar num único modo identitário, ele estará se constituindo numa forma de bailarino como entidade molar. Esta se refere, pois, aos modelos já constituídos em nossa sociedade, aos padrões estabelecidos como formas incontestáveis de conduta. O molar significa o macro, os valores instituídos que nos tomam e nos fazem agir de determinadas maneiras, o que colabora para a manutenção de determinadas formas. Então, pensar o corpo do bailarino como entidade molar significa entendê-lo como um modelo a ser seguido, como se houvesse um caminho já traçado a ser percorrido para o corpo que se põe a dançar ou, ainda, como se existisse um ideal a ser buscado pelo bailarino. O molar evoca uma moral, posturas certas ou erradas, que seguem o modelo ou que se desviam deste. Por isso, supomos que a entidade molar do corpo que dança está ligada à imagem-movimento, ao cronos, ao tempo como sucessão, ao constante aprimoramento da técnica da dança, de um corpo enquanto boa forma, de uma identidade de bailarino bem definida. Pode-se dizer que o molar refere-se a um estado de dominação do corpo e que, portanto, no corpo que dança, isso se dá da mesma maneira. Ao dançar, o bailarino busca um certo aprimoramento da técnica, ele necessita, também, de um tempo como sucessão, contudo, ele não pode parar por aí, caso contrário, o seu dançar irá ficar muito mecânico e restrito. É preciso que ele vá além da dança enquanto modelo a ser seguido, como entidade molar, para que ele possa adquirir uma plasticidade e um tempo complexo no seu dançar.

O corpo pede passagem para além do decalque, precisa se relançar aos devires para se desprender dos seus modelos molares, conquistando, assim, uma dimensão molecular. Esta quebra a lógica molar, já que rompe com os padrões estabelecidos, apostando na força e no movimento das moléculas para produzir o desmanche de sua configuração atual, que implica em microtransformações, encontrando-se na sutileza das pequenas coisas, no quase imperceptível. Desse modo, o devir opera a fim de provocar uma quebra dos padrões molares para a composição de novas texturas numa dimensão molecular, visto que esta provoca uma ruptura dos estados de dominação, com o intuito de compor novas configurações do corpo. Embora o molar e o molecular sejam, num certo sentido, opostos, eles, na realidade, estão num estado de relação, de contato constante. Deleuze e Guattari (1997) salientam que uma dimensão molecular sempre pode escapar à entidade molar, assim como uma forma molecular pode-se transformar num modelo, tornando-se algo da ordem molar. Então, “[...] nenhum fluxo, nenhum devir-molecular escapa de uma formação molar sem que componentes molares os acompanhem, formando passagens ou referências perceptíveis para processos imperceptíveis" 
(DELEUZE; GUATTARI, 1997, p.105). Dessa forma, constatamos que o molar e o molecular colocam-se um movimento contínuo de encontros e desencontros entre o perceptível e o imperceptível, e que o corpo que dança busca atingir uma dimensão molecular, de movimento de moléculas, de velocidade e lentidão, tecendo, assim, novas texturas, ao abrir-se aos seus devires; ou seja, o devir é sempre da ordem do molecular, da ruptura e da quebra de certezas.

Conforme Deleuze e Guattari (1997), todo o devir é minoritário. Cabe lembrar que, para estes autores, maioria e minoria não são explicadas pela superioridade ou inferioridade de um número, ou seja, como algo de ordem quantitativa. A maioria revela, contudo, um padrão, um modelo a ser seguido - sendo da ordem molar - uma busca pela perpetuação da identidade, mesmo que o número não seja superior à minoria. Os mesmos autores falam da maioria como "a determinação de um estado ou de um padrão em relação ao qual tanto as quantidades maiores quanto as menores serão ditas minoritárias" (DELEUZE; GUATTARI, 1997, p. 87). Por outro lado, a minoria se refere à possibilidade de quebrar com os modelos da maioria, sendo da ordem do inventivo, do molecular, e, portanto, da ordem do devir. Trata-se de "entrar num devir-minoritário que o arranca de sua identidade maior” (DELEUZE; GUATTARI, 1997 p.88).

Desse modo, as discussões sobre o molar e o molecular, maioria e minoria, nos levam à questão do devir, que para os mesmos autores (DELEUZE; GUATTARI, 1997), não significa imitar ou seguir um modelo, tampouco se caracteriza a partir de semelhanças ou de atos de identificação. Devir não se refere a relações de parentesco ou a relações formais e também não se faz através da imaginação; além disso, não quer dizer regredir ou evoluir. Antes disso, devir significa "involuir", pois requer a dissolução da forma, a quebra das certezas, a ruptura dos modelos, o que retrata um movimento de involução, ou seja, de criação. Não se pode confundir a involução com uma regressão ao menos diferenciado; involuir significa compor uma forma de evolução que se faz entre heterogêneos. É desse modo que o devir se dá através de uma zona de vizinhança, de um bloco que corre seguindo sua própria linha "entre" os termos, visto que cada elemento heterogêneo não se transforma no outro, criando-se um novo contorno, um novo corpo, que se forma entre eles. Devir implica, portanto, multiplicidade, metamorfose, potência de afetar e de se deixar ser afetado pelos encontros, derivando-se, assim, blocos de devir, que nos levam a novos modos de existência.

Assim, devir bailarino não significa imitar alguém, ou seguir um modelo de bailarino; também não se trata de evoluir a uma forma de bailarino mais elaborada. Trata-se de "involuir", dissolver a própria forma do corpo para liberar tempos e velocidades e, a partir daí, devir bailarino, criando novos modos de ser, novos gestos e expressões. É preciso buscar um modo minoritário de ser bailarino, que não siga padrões, mas que componha o seu contorno a partir de seus blocos de devir - um "entre" os encontros que se dão na dança: entre bailarino e coreógrafo, entre música e corpo que dança, entre bailarinos, entre corpo que dança e coreografia, entre bailarino e público, entre corpo que dança e suas transformações. 
Entendemos que, para temporalizar o corpo que dança, é preciso relançá-lo às possibilidades de devir. Conforme Deleuze e Guattari (1997.), devir é, a partir das formas que se tem, do sujeito que se é, dos órgãos que se possui, extrair partículas, instaurando relações de movimento e repouso, de velocidade e lentidão, a fim de nos tornamos outra coisa. Então, pensar em termos de velocidade e lentidão, de movimento e repouso entre elementos não formados ou relativamente não formados, significa colocar tempo no corpo, subordinando-o a um tempo complexo e paradoxal.

Segundo Deleuze e Guattari (1997), o movimento está numa relação essencial com o imperceptível, uma vez que ele pode ser da ordem do molecular, de velocidades e lentidões entre partículas. Para esses autores, o devir imperceptível conecta-se com o imperceptível, o indiscernível (assignificante) e o Impessoal, remetendo à dimensão molecular e à sutileza de movimentos e permitindo que se extrapole o plano da representação e se estabeleça a conexão ao cosmos, às multiplicidades. É dessa maneira que o devir imperceptível significa devir todo o mundo, o que não é a mesma coisa que ser como todo o mundo, mas, sim, devir todo o mundo. Todo o mundo é o conjunto molar, mas devir todo mundo põe em jogo o cosmo e seus movimentos moleculares. Isto é, trata-se de fazer de todo o mundo um devir, de abrir-se às possibilidades da criação, fazer mundos, vivenciar o cosmo como máquina abstrata, no qual o mundo entra em devir e nós nos tornamos mundo.

Na dança, para devir todo o mundo, é preciso temporalizar o corpo, colocando-o num tempo de coexistência e de complexidade, potencializando-o para que se faça movimentos de mundo, para além dos gestos individuais: uma conexão às forças do Impessoal. É necessário, pois, desprender-se do antigo "eu" que dançava, do antigo corpo, e temporalizá-lo, lançando-o a velocidades e lentidões, a uma dimensão sutil, uma potência de devir e de se transformar em novas matérias de expressão. $\mathrm{O}$ corpo que dança pode compor movimentos extremamente velozes em suas moléculas, muito acima do limiar da percepção; ou, paradoxalmente, pode-se realizar movimentos extremamente lentos, muito aquém da percepção, mas que trazem mudanças essenciais no corpo. Isso propiciará uma maior plasticidade no corpo do bailarino e o colocará em relação com o devir. E eis que surge o paradoxo: o movimento é imperceptível e, ao mesmo tempo, pode ser percebido. A percepção torna-se, assim, molecular, já que ela adquire uma sensibilidade de captar a dimensão sutil do movimento.

Nesse sentido, relacionamos o conceito de devir imperceptível à questão das pequenas percepções, tema abordado por José Gil (2003). Segundo esse autor, o corpo pode tornar-se uma espécie de órgão de captação das mais finas vibrações do mundo. O corpo pode dar inúmeros sinais, através das pequenas percepções, que são aparentemente indetectáveis pelos sentidos, mas que podem, portanto, se tornar percebíveis. O corpo, pela captação das pequenas percepções, pode perceber movimentos inicialmente imperceptíveis. Trata-se de um "não sei quê", um "qualquer coisa", microscópico, nada que seja visto ou ouvido. Significa o intervalo entre uma percepção macroscópica habitual e sua percepção atual; portanto, 
a pequena percepção é "intervalar", situa-se no "entre", no neutro, no meio de passagem. Apesar disso, ela tem uma forma, que não descreve uma figura ou um contorno definido, uma vez que esse intervalo é percebido enquanto forma de forças que emanam do conjunto das pequenas percepções. Nada se vê, nada de ouve, mas sente-se qualquer coisa indeterminada e ilocalizável, que é sentido pelo corpo inteiro. Gil (2003) chamou a isso de "contorno do silêncio" ou "contorno da ausência".

Ao dançar, o bailarino abre seu corpo para captar as mais finas vibrações, ele ativa sua sensibilidade, seus sentidos, para atrair a energia do mundo, de uma forma sutil, leve, que o faça transportar a novas passagens. Ele precisa se comunicar com as ausências e com os silêncios do seu corpo, dar-lhes contorno e, assim, potencializar o surgimento de novos corpos. Isso o coloca numa outra dimensão temporal. Colocar tempo no corpo pode significar abri-lo ao regime do sutil, ao devir imperceptível, às velocidades e lentidões, às pequenas percepções, ao vir a ser. Como diz Denise Sant'Anna (2003), trata-se de um plano de composição que prescinde da dominação entre termos, em que o corpo sutil e as vertigens sutis emergem. A vertigem sutil contém o paradoxo de transformar algo ao mesmo tempo no mais conhecido e no mais enigmático. $\mathrm{O}$ corpo que dança, então, arrisca-se num gesto que é clichê e, também, completamente absurdo. Esse é um dos desafios - brincar com as certezas e os estranhamentos, com os paradoxos da própria imagem, de uma forma sutil, quase imperceptível...

\section{REFERÊNCIAS}

ALLIEZ, E. Deleuze: Filosofia Virtual. São Paulo: Ed 34, 1996.

DELEUZE, G. Bergsonismo. São Paulo: Ed 34, 1999.

. A imagem-tempo: cinema 2. São Paulo: Brasiliense, 1990.

. A Imanência: uma vida. Educação \& Realidade, Porto Alegre, v. 27, n. 2 , p. 10-18, 2002.

; GUATTARI, F. Mil Platôs: capitalismo e esquizofrenia. São Paulo: Ed 34, 1995. v. 1.

v. 4.

Mil Platôs: capitalismo e esquizofrenia. São Paulo: Ed 34, 1997.

; PARNET, C. Diálogos. São Paulo: Escuta, 1998.

GIL, J. Abrir o corpo. 2003. Palestra proferida no Simpósio Corpo, Arte e Clínica. Porto Alegre, Universidade Federal do Rio Grande do Sul - UFRGS, PPG em Psicologia Social e Institucional.

. Movimento total: o corpo e a dança. [s. 1.]: Relógio D’Água, 2001.

PELBART, P. P. Da clausura do Fora ao Fora da clausura: loucura e desrazão. São Paulo: Ed Brasiliense, 1989. 

. O tempo não-reconciliado. São Paulo: Perspectiva: FAPESP, 1998.

SANT'ANNA, D. B. Vertigens do corpo e da clínica. 2003. Palestra proferida no Simpósio Corpo, Arte e Clínica. Porto Alegre, Universidade Federal do Rio Grande do Sul - UFRGS, PPG em Psicologia Social e Institucional.

SCHÉRER, R. Homo Tantum: o impessoal: uma política. In: ALLIEZ, Éric (Org.). Gilles Deleuze: uma vida filosófica. São Paulo: Ed. 34, 2000.

SILVA, A. do E. Voltar as costas para o tempo: o problema da subjetividade em Bérgson. In: - Saúde Loucura - Subjetividade. São Paulo: Hucitec, data.

Recebido em dezembro/2004 Aceito em abril/2005 
